\title{
ENTRE SEGUIR E QUEBRAR PARADIGMAS NO ENSINO DE IDIOMAS: UM RELATO DE EXPERIÊNCIA NA ATIVIDADE DOCENTE DO CELIN UFPR
}

\author{
Between following and breaking paradigms in language teaching: \\ an experience report about the teaching activities at Celin UFPR
}

\author{
João Victor SCHMICHECK \\ Universidade Federal do Paraná \\ victorschmicheck@gmail.com \\ https://orcid.org/0000-0001-7402-8485 \\ Marena Carolina LESSKIU \\ Universidade Federal do Paraná \\ marena.lesskiu@gmail.com \\ https://orcid.org/0000-0001-5343-4281
}

\begin{abstract}
RESUMO: O Centro de Línguas e Interculturalidade (Celin) da Universidade Federal do Paraná (UFPR) foi criado como um espaço para a formação inicial e continuada de professores de línguas e para promover a democratização do ensino e aprendizado de idiomas em Curitiba. Todavia, autores como Halu e Fogaça (2018) evidenciam uma adequação dos cursos do Celin aos modelos pedagógicos tradicionais e apontam um possível distanciamento dos objetivos iniciais da instituição. De modo a investigar essa questão, realizamos um estudo etnográfico que se dividiu em duas frentes: i) a percepção dos alunos quanto à metodologia utilizada nos cursos de inglês do Celin, bem como as formas de avaliação realizadas e a estrutura do curso; ii) a visão dos alunos quanto à figura do professor estagiário. Discutimos essas questões por meio de reflexões e análises de dados gerados por um questionário e uma roda de conversa realizados com alunos da área de inglês entre 2018 e 2019. Os resultados nos mostram que existem diversos estereótipos a respeito dos estagiários e que elementos de uma concepção estruturalista de língua podem ser observados, mas que o Celin continua a ser um espaço democrático de ensino e aprendizado, formação e constante reflexão.
\end{abstract}

PALAVRAS-CHAVE: Celin UFPR; Ensino de Línguas; Formação de Professores; Professores Estagiários.

ABSTRACT: The Center for Languages and Interculturality (Celin) of the Federal University of Paraná (UFPR) was created as a space for the initial and continuous training of language teachers and to promote the 
democratization of language teaching and learning in Curitiba. However, authors such as Halu and Fogaça (2018) show an adaptation of Celin's courses to traditional pedagogical models and point to a possible divergence from the institution's initial goals. In order to investigate this issue, we conducted an ethnographic study that was divided into two fronts: i) the students' perception about the methodology used in Celin's English courses, as well as the forms of assessment carried out and the structure of the course; ii) the students' view of the trainee teacher. We discussed these issues through reflections and analysis of data generated through a questionnaire and an interview held with students in the English area between 2018 and 2019. The results show that there are several stereotypes about the trainees and that elements of a structuralist conception of language can be observed, but that Celin continues to be a democratic space for teaching and learning, as well as training and constant reflection.

KEYWORDS: Celin UFPR; Language Teaching; Teacher Training; Trainee Teachers.

\section{INTRODUÇÃO}

Criado em 1995, o Centro de Línguas e Interculturalidade (Celin) surgiu de discussões realizadas em reuniões do Departamento de Línguas Estrangeiras Modernas (DELEM), adjunto aos cursos de Letras da Universidade Federal do Paraná (UFPR). Nesses encontros, nos quais professores buscavam alternativas que ajudassem a suprir a demanda de ensino de línguas instrumentais que o DELEM já não conseguia atender, começou-se a idealizar um projeto de extensão que teve entre seus principais objetivos não apenas a instrumentalização dos alunos para a leitura de textos em outras línguas, mas também a busca pela democratização do ensino de idiomas e a promoção de trocas culturais na cidade de Curitiba. Um centro de línguas com caráter universitário poderia oportunizar mais acesso à sua comunidade interna e externa a cursos de idiomas de qualidade, bem como ampliar as ações de extensão interculturais. Desse modo, o Celin era visto como um espaço potencial para o entrelaçar entre pesquisa, ensino, formação e extensão universitária.

Outro fator que incentivou a criação do Celin foi o fomento de uma instituição que proporcionasse oportunidades de formação docente, onde alunos dos cursos de Letras da UFPR pudessem ter "um espaço para pensar a prática pedagógica e desenvolver pesquisas na área de línguas e culturas" (UFPR, 2015, p. 20). Ou seja, o Celin surgiu como um 
espaço no qual, além de viabilizar o ensino de diversas línguas e culturas, se promoveu e ainda se promove a busca por uma maior qualidade de ensino a partir da pesquisa e da formação inicial e continuada de seus professores. Portanto, o Centro de Línguas e Interculturalidade é um ambiente onde seria possível extrapolar os formatos tradicionais de ensino e aprendizagem de línguas, colocando em prática abordagens inovadoras discutidas nas salas de aula universitárias.

Todavia, autores como Halu e Fogaça (2018) apresentam um cenário que problematiza a realidade encontrada atualmente no Celin. Em um diálogo reflexivo recentemente publicado, cujo foco principal da conversa é a expansão da língua inglesa e como isso afeta a ação docente de professores de inglês nos cursos de Letras, Halu e Fogaça relatam brevemente as experiências que vivenciaram como coordenadores da área de inglês do Centro de Línguas e Interculturalidade da UFPR. Halu conta que aquilo que mais a incomoda no Celin é "o fato de que ele funciona de fato como uma escola de línguas regular, com tendência para reproduzir o ensino calcado no uso de livros didáticos importados, na adoção de um syllabus gramatical-funcional a ser seguido", indo além ao declarar que há "pouco espaço para propostas alternativas ou pesquisas vinculadas à implantação de cursos com formato inovador" (HALU; FOGAÇA, 2018, p. 11).

Com o passar de mais de vinte anos, portanto, os objetivos que levaram à criação e ao crescimento de uma instituição como o Celin talvez estejam passando por um processo de mudança. Como ex-estagiários, também da área de inglês do Centro de Línguas e Interculturalidade da UFPR, concordamos com as reflexões de Halu e Fogaça (2018). Se retomarmos os objetivos constituintes da instituição e os relacionarmos aos apontamentos dos autores, talvez seja possível dizer que há uma adequação dos cursos do Celin aos moldes tradicionais do ensino de línguas, o que acaba resultando em uma diminuição do espaço para formação e experimentação em busca de novas estratégias e metodologias e impossibilita a promoção de uma desconstrução de paradigmas e concepções tradicionais sobre o que seriam as línguas e como entender seu ensino e aprendizado.

Quando nos referimos a cursos tradicionais, estamos pensando em instituições que, muitas vezes, promovem um ensino pautado em (e vendido como) métodos "milagrosos" - baseados em materiais didáticos quase sempre desenvolvidos por falantes nativos sem conhecimento da realidade em que os recursos serão aplicados - e que têm o falante nativo 
como parâmetro de proficiência e até mesmo como comunidade almejada. Além disso, práticas de ensino de línguas caracterizadas como tradicionais normalmente não se voltam a questões de caráter mais epistemológico, como depreende-se da não preocupação em discutir conjuntamente com seu grupo docente questões sobre concepção de língua.

Refletindo sobre essas questões, nos sentimos especialmente inquietos ao ler os objetivos acadêmicos da instituição, apresentados na publicação comemorativa RELATÓRIO 20 ANOS DE CELIN: 1995 - 2015:

\begin{abstract}
Academicamente, o Celin tem os seguintes objetivos: a) o ensino de línguas e culturas com qualidade; b) a formação inicial e continuada dos professores estagiários - alunos dos cursos de graduação em Letras da UFPR, dos instrutores de línguas já formados nos cursos de Letras da UFPR e de alunos de mestrado e doutorado da UFPR ou de universidades conveniadas, buscando torná-los profissionais de qualidade e em sintonia com o mercado de trabalho; e c) servir de espaço para sonhar e ousar com projetos que tenham impacto na comunidade interna à UFPR e que possam transformar a sociedade em que a UFPR está inserida (UFPR, 2015, p. 34, grifo nosso).
\end{abstract}

Essa inquietação se dá, principalmente, em relação ao item b, que declara como um dos focos da instituição a promoção da "formação inicial e continuada dos professores". Ao longo de nossa prática como estagiários ${ }^{1}$, percebemos certo estranhamento dos alunos em relação à ideia de ter aulas com professores ainda no início de sua formação docente. Além disso, a própria área de inglês parecia estar adquirindo um caráter muito similar ao dos cursos de idioma tradicionais, ou seja, desenvolvendo um trabalho com foco nas demandas do mercado de ensino de idiomas, ignorando a proposta inicial do Celin como instituição de pesquisa e formação docente, bem como limitando o acesso às experiências iniciais de docência por parte dos alunos de Letras em processo de formação inicial.

Sendo assim, realizamos uma pesquisa qualitativa de caráter etnográfico (BORTONI-RICARDO, 2008) com alunos do curso de inglês do Celin, buscando averiguar suas perspectivas sobre o Centro de Línguas e Interculturalidade como um espaço de pesquisa e extensão. Fazendo uso de dados gerados por meio de um

\footnotetext{
${ }^{1}$ Durante a realização do estudo o Celin contava com dois tipos de professores: os estagiários, alunos da graduação e pós-graduação em Letras, e os cooperados, professores contratados por meio de uma cooperativa que prestava serviços à instituição. Esses professores contratados podiam ser tanto membros da comunidade interna da UFPR quanto ex-alunos e/ou professores formados em outras instituições.
} 
questionário e de uma roda de conversa, realizados com grupos diferentes de alunos e em momentos distintos, pretendemos problematizar o seguinte questionamento: estaria o Celin se distanciando de seus objetivos formadores à medida que adquire traços que remetem a características de escolas tradicionais de ensino de línguas?

\section{O PERCURSO DO ESTUDO}

Em primeiro lugar, este texto se constrói como um relato de experiências em um contexto específico e único. Por essa razão, para o tipo de contribuição que se propõe, entendemos que explicitar nosso lócus de enunciação é de extrema importância (FIGUEIREDO; MARTINEZ, 2019). Sendo assim, somos dois ex-estagiários da área de inglês do Centro de Línguas e Interculturalidade da UFPR. Na época em que o estudo se desenvolveu, éramos ambos estudantes de Letras Inglês da UFPR, uma universidade reconhecida como um dos polos educacionais do Sul do Brasil. Este relato, portanto, é fruto de nossa experiência como estagiários entre os anos de 2017 e 2019 no Celin e acreditamos que esclarecer o "lugar" do qual falamos possa ajudar nosso leitor a entender como chegamos a essas considerações.

O início da pesquisa se deu no segundo semestre de 2018, com dados gerados por meio de um questionário piloto (ANEXO 1). O questionário, em formato on-line, foi aplicado com as turmas dos cinco professores estagiários atuando na área de inglês na época. Como os participantes responderam de forma anônima e voluntária, obtivemos 22 respostas entre os alunos das cinco turmas ${ }^{2}$. Tendo em vista que nosso objetivo principal era realizar uma sondagem inicial, não fizemos perguntas sobre o perfil de cada um desses alunos. Focamos, portanto, em averiguar a percepção desses alunos do Celin a respeito de dois aspectos: i) suas motivações em escolher o Celin para aprender inglês, suas experiências dentro do centro e em comparação com experiências anteriores e sua opinião sobre as avaliações utilizadas; ii) a presença do professor estagiário em sala de aula, tendo em vista nossa asserção de que a figura do estagiário estaria perdendo espaço dentro da instituição mesmo constando como um dos objetivos formadores do Celin.

\footnotetext{
${ }^{2}$ Como essa etapa foi apenas um diagnóstico inicial, não controlamos o número de alunos em cada uma das cinco turmas. Todavia, na época em que o estudo foi realizado, as turmas da área de inglês tinham em média 12 alunos.
} 
A segunda fase de geração de dados ocorreu no ano seguinte. No primeiro semestre de 2019, com o intuito de aprofundar essas reflexões por meio de uma pesquisa qualitativa etnográfica (ANDRÉ, 2012; BORTONI-RICARDO, 2008), revisitamos algumas das questões do questionário on-line durante uma entrevista semiestruturada em formato de roda de conversa. Essa roda de conversa foi realizada em uma turma de nível pré-intermediário do curso de inglês do Celin, composta por seis alunos, dos quais três já estavam cursando inglês no Celin havia alguns semestres e três eram novos alunos, alocados na turma de pré-intermediário após exame de nivelamento. Todos os alunos assinaram um termo de consentimento e participaram voluntariamente da pesquisa.

É importante explicitar que um dos autores deste estudo era o professor titular deste grupo em questão. Por esse motivo, o professor estagiário se ausentou durante a roda de conversa para que os alunos se sentissem mais confortáveis em responder às perguntas, cabendo à outra pesquisadora atuar como mediadora da discussão. A discussão se baseou em um roteiro formulado previamente (ANEXO 2), mas esse não foi seguido à risca, uma vez que o intuito era guiar e não restringir a conversa.

Sendo assim, na seção seguinte apresentaremos as análises que construímos a partir da roda de conversa e, vez ou outra, iremos resgatar algumas das respostas obtidas a partir dos questionários aplicados em 2018. Isso se dá não apenas por esse ter sido o passo inicial que motivou o aprofundamento da pesquisa que compartilhamos neste relato, como também para mostrar como certos pontos de vista podem aparecer em ambos os contextos. Entendemos também que nossa análise e reflexão pautam-se no entrelaçar das experiências que vivenciamos no Celin, por isso aproximar os dados gerados nos questionários e na roda de conversa é significativo para nós. As asserções que guiaram nossa investigação foram: i) o Celin possui um caráter formador, mas esse parece estar se perdendo ao longo dos anos; ii) essa perda se manifesta na forma como os cursos da área de inglês são estruturados; e iii) essa perda também pode ser observada na área de inglês no que diz respeito à formação inicial, i.e. na presença (e na falta) dos estagiários.

Assim como no questionário on-line, as perguntas feitas durante a roda de conversa enfatizavam dois aspectos centrais: i) a percepção dos alunos quanto à metodologia utilizada nos cursos de inglês do Celin, bem como as formas de avaliação realizadas e a estrutura geral do curso; e ii) a percepção dos alunos quanto à presença do 
professor estagiário em sala de aula. Escolhemos uma metodologia qualitativa, pois, como apontamos, estamos tentando entender mais sobre "um processo que ocorre em um determinado ambiente e quer[emos] saber como os atores sociais envolvidos nesse processo o percebem, ou seja: como o interpretam.” (BORTONI-RICARDO, 2008, p. 34).

Nas próximas seções iremos, primeiro, descrever a roda de conversa e a discussão, resgatando as perguntas feitas por nós e as respostas dadas pelos alunos tanto na roda de conversa quanto nos questionários. Para manter o anonimato dos participantes, quando retomamos as falas dos alunos, usamos uma numeração de 1 a 6 , baseada na ordem com que cada aluno se introduziu no início da entrevista. Em seguida, iremos confrontar os dados encontrados com leituras que auxiliaram nosso entendimento quanto ao conteúdo encontrado durante a pesquisa.

\section{A RODA DE CONVERSA}

A roda de conversa foi realizada no final de uma aula regular da turma do professor estagiário e foi conduzida pela pesquisadora que não atuava como docente deste grupo. Os alunos tinham conhecimento de que estavam participando de uma pesquisa, portanto a roda de conversa foi gravada para análise posterior. Como mencionado anteriormente, o roteiro de perguntas preparado previamente teve dois enfoques e buscava explorar a percepção dos alunos a respeito dessas questões. Os resultados do momento de reflexão com os participantes são explorados a seguir de acordo com essa distinção dos eixos i e ii de análise.

\section{Metodologia e avaliações do curso de inglês do Celin}

A primeira pergunta buscava averiguar como os alunos conheceram o Celin e o que os levou a escolher a instituição para aprender inglês. As respostas foram, em grande parte, unânimes. Quase todos os alunos chegaram até o Celin por meio de indicações de terceiros e a escolha teria se dado por conta do vínculo do centro com a Universidade Federal do Paraná (UFPR), o que facilitaria a entrada na instituição. Além disso, os alunos afirmaram, mais de uma vez, que outros fatores importantes para a escolha foram as recomendações positivas em relação à qualidade de ensino e o preço mais acessível em 
comparação a outros lugares. Por fim, a Aluna 1 mencionou ainda a oportunidade de receber uma bolsa de estudos do Celin e que isso proporcionou a ela o aprendizado de outro idioma. Ou seja, quando resgatamos o fato de que um dos objetivos formadores do Celin seria o de promover a democratização do ensino e aprendizagem de línguas em Curitiba, verificamos que essa característica ainda é bastante viva no imaginário dos alunos, que veem a instituição como uma escola que oferece um ensino de boa qualidade e de forma acessível ${ }^{3}$.

O segundo tópico abordado durante a roda de conversa buscava realizar uma rápida investigação quanto às experiências anteriores desses alunos em relação ao aprendizado de inglês. Para encorajar respostas mais aprofundadas, também pedimos aos alunos que sinalizaram experiências anteriores para que as comparassem com suas experiências no Celin. A maioria dos alunos já tinha uma experiência anterior. Alguns deles mencionaram a escola ou realidades bastante diferentes das que se encontram no Centro de Línguas da UFPR ${ }^{4}$ e outros apontaram realidades mais parecidas. O Aluno 6, por exemplo, estudou em um centro de línguas de outra instituição federal e disse que as realidades eram bastante similares, com a única diferença entre as duas experiências sendo a de que o outro curso teria menor duração. A Aluna 2 mencionou ter estudado inglês anteriormente, durante sua graduação na cidade de Santa Maria (RS), onde o curso parecia acompanhar um material didático diferente, portanto, em sua opinião, tinha uma abordagem diferente - "mais palavra por palavra, [focando em] pronúncia" (ALUNA 2). No Celin, o foco seria outro, uma vez que, na visão da aluna, os aprendizes têm mais oportunidades de praticar conversação, pois os professores parecem prezar pela interação dos alunos. Foi possível observar na compreensão da aluna que ela entende o material

\footnotetext{
${ }^{3}$ Isso aparece também nos dados obtidos com o primeiro questionário, como na resposta de um aluno anônimo: "Para mim significa uma oportunidade de estudar em uma escola de idiomas com relativa boa qualidade e perfeitamente acessível para mim. Significa a oportunidade de me tornar um profissional mais qualificado e abre as portas para novas oportunidades através do aprendizado de uma língua indispensável. Agradeço a Deus e tenho muito ORGULHO do trabalho do Celin, pois não sei se poderia cursar outro idioma em uma escola tradicional." (Aluno anônimo em resposta ao questionário on-line).

${ }^{4} \mathrm{O}$ aluno 4 estudou inglês por bastante tempo durante a infância. Todavia, segundo ele, por meio de um método bastante diferente daquele que se segue no Celin, sendo algo bastante prático e que teria possibilitado um aprendizado significativo de vocabulário. A descrição do aluno parece se encaixar nos moldes da metodologia CLIL (Content and Language Integrated Learning). O aluno 5 relatou uma experiência de aprendizado com um curso durante seu período no exército. Essa, por sua vez, teria sido majoritariamente instrumental, tendo em vista que o curso era focado em leitura e em formato EAD, não possibilitando que o aluno praticasse conversação.
} 
didático como uma influência significativa na metodologia abordada pelo curso de inglês do Celin. Isso parece ser um dos elementos que aproximam o centro de uma realidade mais tradicional do ensino de línguas pautado em um livro didático e sem a produção de um material próprio voltado ao seu público local.

$\mathrm{Na}$ sequência, questionamos os alunos sobre quais seriam suas motivações para aprender inglês. Em linhas gerais, a turma apontou seus currículos profissionais e acadêmicos como os principais motivos. Para alguns, o conhecimento de inglês já deixou de ser um diferencial e se tornou uma necessidade básica. No entanto, a maioria dos alunos afirmou que não está aprendendo a língua apenas pela necessidade de mercado, mas que também estudam inglês tanto por lazer (para o consumo de séries, filmes, músicas e jogos lançados originalmente em língua inglesa) quanto para que possam ter autonomia durante futuras vivências internacionais (tais como viagens, estudos no exterior ou imigração).

A pergunta então se desdobrou ao questionar os alunos se eles acreditam que o Celin irá ajudá-los a alcançar esses objetivos em relação ao aprendizado de inglês. A maioria disse acreditar que sim, principalmente por conta das aulas propiciarem práticas de conversação. O Aluno 5, inclusive, após alguns semestres estudando no Celin, afirmou já ver uma grande melhoria em sua compreensão e expressão na língua estrangeira. Alguns, todavia, não estavam tão certos quanto a esse ponto. Isso se dá pelo fato de que, até então, o curso geral de inglês do Celin apresentava nove níveis ${ }^{5}$, cuja nomenclatura gerava algumas confusões. Sendo assim, mais de um aluno mencionou que, ao final dos níveis intermediários, talvez precisassem buscar outra instituição para que pudessem cursar os níveis avançados. Porém, em resposta, a pesquisadora lança uma provocação ao sinalizar que os níveis intermediários do Celin seriam bastante avançados em comparação com outras escolas. Esses mesmos alunos, então, passaram a ponderar sobre seu posicionamento, dizendo que o nome dado aos níveis gerava certa dúvida, mas que já no pré-intermediário sentiam que estavam mais avançados do que antes e que só poderão saber ao final do curso se os seus objetivos foram alcançados.

\footnotetext{
${ }^{5}$ Em 2019, esses nove níveis estavam divididos em: três níveis básicos (Básicos 1, 2 e 3), três níveis préintermediários (Pré-Intermediários 1, 2 e 3) e três níveis intermediários (Intermediários 1, 2 e 3). Além disso, havia turmas especiais (e.g. de conversação e compreensão de textos) abertas de acordo com a demanda dos alunos. Mais informações disponíveis em: <http://www.celin.ufpr.br/index.php/cursos/cursos-do-celin/16catalogo-eletronico-de-cursos/114-ingles-lingua-e-cultura >. Acesso em: 23 jun. 2020.
} 
Acreditamos que essa divisão de cursos exclusivamente por níveis de proficiência também pode ser vista como um dos elementos que aproxima o Celin de modelos mais tradicionais no ensino de línguas, nos quais a passagem de um nível para outro representaria um "aumento" na quantidade de conhecimento do aprendiz. Se trata de uma configuração que, de partida, entende o aprendizado de uma língua como um fenômeno linear, passível de ser avaliado por meio de parâmetros discretos e pautado em padrões e códigos linguísticos pré-estabelecidos. Essa discussão, por sua vez, será retomada na seção seguinte.

Em sequência, perguntamos aos alunos quais eram suas percepções quanto às avaliações conduzidas durante os cursos de inglês do Celin. Essa pergunta também vai ao encontro de nossa compreensão de que a área estaria seguindo cada vez mais métodos tradicionais de ensino e aprendizado de línguas, pois os cursos não apenas são bastante formulados em cima de um livro didático pré-estipulado, construído por um falante nativo que não conhece a realidade na qual o material será utilizado, como também as avaliações se dividem nas habilidades tradicionalmente conhecidas por Reading, Listening, Writing e Speaking, tais quais muitas instituições que vendem cursos preparatórios e testes de proficiência. Além disso, no momento em que a pesquisa foi realizada, a área ainda mantinha dois testes de gramática ao longo de cada nível ${ }^{6}$. Sendo assim, se pensarmos o Celin como uma instituição que tem como um de seus objetivos a experimentação de metodologias atualizadas de ensino, esses métodos avaliativos parecem entrar em conflito com as perspectivas abordadas nos cursos de Letras que se propõem a estudar Letramento Crítico (FOGAÇA; JORDÃO, 2007, JUCÁ; FUKUMOTO; ROCHA, 2011) e concepções de língua pós-estruturalistas (JORDÃO, 2006), por exemplo.

Ainda que alguns alunos tenham manifestado a vontade de participar de atividades menos tradicionais durante as aulas, tais como a promoção de um book club, no qual os alunos possam fazer atividades relacionadas à leitura de textos literários, a maioria concorda com todas as avaliações (provas e testes realizados) e acha que estão bem distribuídas, permitindo que todos os alunos "obtenham sucesso" em seu aprendizado,

\footnotetext{
${ }^{6}$ Esses testes de gramática eram chamados de Progress Check e, depois de muitas discussões a respeito dos objetivos dessas avaliações dentro da área, foram removidos do quadro de avaliações no segundo semestre de 2019. Eles eram aplicados de forma a avaliar a memorização de pequenas regras gramaticais de forma isolada - e.g. exercícios para preencher lacunas, reorganizar a ordem de frases, etc.
} 
pois ainda que sejam mais "fortes" em certos aspectos e mais "fracos" em outros, a maioria consegue atingir uma boa nota: "Tem alguns que têm mais facilidade com o listening. Eu já não tenho. Você acaba compensando as suas dificuldades em um ou em outro." (ALUNO 5).

As respostas que obtivemos por meio do questionário on-line nos revelam opiniões muito semelhantes acerca das avaliações. Perguntamos aos alunos quão úteis eles julgavam as avaliações e disponibilizamos a eles uma escala de um a cinco, em que um era considerado "inútil/dispensável" e cinco "extremamente importante". De modo geral, os alunos acreditam que todas as provas e testes são de extrema importância ou apenas importantes, com exceção da prova voltada exclusivamente aos conhecimentos de gramática, a qual foi considerada pela maioria dos alunos como um três na escala, ou seja, "neutro".

Acreditamos que, por estarem mais familiarizados com estratégias tradicionais de avaliação, esses alunos associam o sucesso de seu aprendizado com o valor numérico de suas notas finais obtidas nas provas e testes. Desse modo, os alunos acabam preferindo meios de avaliação já conhecidos, pois acreditam que esses sejam as melhores formas de averiguar se estão fixando os conteúdos trabalhados ao longo do curso. É importante esclarecer neste ponto que não estamos criticando as formas de aprendizado de cada aluno, mas sim problematizando essa separação das habilidades (falar, escrever, ler e escutar), avaliadas individualmente, como se fossem independentes entre si no aprendizado de um idioma, quando poderiam ser trabalhadas de forma integrada, compreendendo a língua como prática social - i.e. uma troca entre sujeitos reais localizados em contextos específicos - e não como um sistema fixo de regras que precisam ser seguidas da mesma forma por todos para que a comunicação possa acontecer.

\section{A figura do estagiário}

Dando continuidade à roda de conversa realizada com os alunos, a segunda parte da discussão tratou da percepção dos alunos quanto à posição dos estagiários na área de inglês do Celin. Uma de nossas asserções no início deste estudo era a de que o Celin estaria perdendo um de seus caráteres formadores à medida que os estagiários perdem seu 
espaço dentro da instituição ${ }^{7}$. Sendo assim, a primeira pergunta buscava questionar se os alunos já haviam tido aulas com professores estagiários. A maioria afirmou não ter certeza, pois os professores muitas vezes não falam sobre serem estagiários ou não. $\mathrm{O}$ Aluno 6 chegou a perguntar se seria o caso do seu professor atual. A pesquisadora, no intuito de fazê-los falar mais a respeito do assunto, retornou o questionamento ao aluno, o qual respondeu que não tinha certeza. Os demais, por sua vez, acreditavam que o professor atual já seria contratado.

Seguindo nessa direção, perguntamos aos alunos a opinião deles sobre estagiários atuando como docentes no Celin. A Aluna 1 relatou que em sua graduação, no curso de Psicologia, já teriam conduzido um estudo no qual os pesquisadores discutiram se o Celin seria realmente voltado para a formação de professores ou não, pois não havia uma compreensão compartilhada com a comunidade de alunos do Celin se os professores que atuam no centro são estagiários de Letras ou professores já contratados. Todavia, a aluna não se aprofundou nesse relato. O nosso entendimento, entretanto, é de que, por conta do contato prévio com essas discussões, ela entenderia que estudar no Celin é ter aulas com professores ainda em formação. Mais além, essa mesma aluna relacionou o fato de os níveis oferecidos nos cursos de inglês do Celin estarem organizados apenas até o Intermediário com o fato de os professores estarem em formação: "eu lembro que na época a gente discutiu sobre [o Celin] ser voltado para a formação de professores. Então, talvez, tenha a ver e faça sentido também com a nomenclatura, de ir até o intermediário." (ALUNA 1). A nossa compreensão acerca do que essa aluna quis dizer é de que docentes ainda em formação, sejam eles estagiários ou professores já contratados, talvez não consigam dar aula de inglês "avançado". Posteriormente, a aluna contraditoriamente disse que os professores só irão aprender a lecionar na prática, mas que ter aula com os estagiários a deixaria mais insegura.

Por conta desse comentário, a pesquisadora a questionou sobre esse sentimento de insegurança. Isso resultou em outro relato, por parte da mesma aluna, de quando teria participado da primeira turma de um professor recém-contratado. Ela acredita que "não foi uma experiência tão rica” (ALUNA 1) em questão de aprendizado. A aluna afirmou "senti[r] falta de professores que estavam aqui há um pouco mais de tempo" (ALUNA 1),

\footnotetext{
${ }^{7}$ Durante a realização deste estudo, a área de inglês contava com 4 estagiários. Em comparação, eram 24 
ainda que esse professor tivesse dado aulas em outro lugar anteriormente, pois sentiu falta de certo "traquejo" para com as práticas da instituição. A mediadora a questionou então sobre ter aulas com um estagiário que já teria pego turmas anteriormente e, para a aluna, esse não seria um problema. Ou seja, a questão parece ser mais o tempo de experiência do professor com os procedimentos do Celin do que ser estagiário ou contratado. Todavia, entendemos que se trata de um discurso complexo e repleto de possíveis outras interpretações.

O Aluno 5, por sua vez, relatou também já ter tido aula com uma professora que estaria assumindo sua primeira turma: "Recém-contratada. Acho que não teve dificuldade. A professora foi muito bem. [...] Ela falou que era a primeira turma dela." (ALUNO 5). A Aluna 2, de forma semelhante, afirmou acreditar que "o professor, às vezes, quando é estagiário, talvez ele se dedique um pouco mais para a turma e se preocupe mais com o aprendizado". Ao que o Aluno 5 respondeu: "quer mostrar mais serviço, não é?”. A aluna então afirmou não ter problema, "contanto que não prejudique o aprendizado. Que a gente consiga aprender é o mais importante, independentemente se é estagiário ou contratado." (ALUNA 2) ${ }^{8}$. Com esse comentário ela acabou conduzindo a um tipo de consentimento de outros participantes da roda de conversa.

Nesse ponto os discursos a respeito da figura do estagiário passam a se mostrar bastante complexos. A mesma aluna (Aluna 1) que relatou talvez se sentir insegura em ter aulas com estagiários afirmou que o professor com quem estava tendo aulas no semestre em questão seria um professor muito dedicado. Como já mencionado anteriormente, esse professor era um dos estagiários da área de inglês no momento da pesquisa. Essa é uma das reflexões que gostaríamos de destacar ao longo deste relato: a mesma aluna que afirmou talvez se sentir insegura em ter aula com professores iniciantes elogiou a competência de um professor estagiário com quem teve aulas ao longo do semestre porém, sem o conhecimento de que esse era estagiário naquele momento. Ou seja, a posição assumida pelos estagiários, ainda que estejam em um centro cujo um dos objetivos principais é a formação inicial, é de bastante conflito: parece haver um estereótipo

\footnotetext{
professores já contratados.

${ }^{8}$ É possível perceber a semelhança desse discurso com uma das respostas anônimas que obtivemos no questionário on-line: "Acredito que a competência técnica e o comprometimento sejam mais importantes do que a palavra estagiário nesse contexto. E eu, em particular, senti que os estagiários do Celin são bastante competentes e comprometidos." (Aluno anônimo em resposta ao questionário on-line).
} 
(HALL, 2005) que não representa, necessariamente, a realidade. Iremos voltar a esse ponto na próxima seção.

A discussão começou a mudar quando o Aluno 6 fez o seguinte questionamento à entrevistadora: "Quando você fala de ter aula com estagiário, você fala o semestre inteiro?". Neste momento, o aluno antecipou uma questão que havíamos planejado para mais adiante na roda de conversa. Ele disse perguntar isso pois teria tido aula com estagiários em vários momentos ao longo de sua formação escolar e universitária e sentia que essas experiências não haviam sido proveitosas: "Claro que é importante que o estagiário dê aula para ele aprender, para ser um professor, só que eu acho que ele não deve pegar uma turma para um semestre inteiro." O aluno foi além ao acrescentar: "Talvez ele devesse dar algumas aulas, uma ou duas, com a supervisão do seu orientador, só para pegar um pouco de experiência, mas dar aula mesmo eu acho que não é proveitoso." (ALUNO 6). Isso acabou levantando uma questão não antecipada quando pensávamos o estudo: estaria sendo suficiente - tanto para os alunos quanto para os estagiários - a supervisão dos estagiários durante as aulas do Celin? De nossa experiência como exestagiários da instituição, acreditamos que a problemática levantada pelo aluno é válida.

Naquele momento, com o intuito de dar sequência à roda de conversa com os alunos, a pesquisadora optou por adaptar o roteiro preparado previamente. Inicialmente, havíamos pensado em perguntar para aqueles que já tiveram aulas com professores contratados se eles perceberam alguma diferença em relação aos estagiários. Todavia, como os alunos mencionaram não saber se teriam tido aula com estagiários ou não, a mediadora direcionou a discussão para as percepções dos alunos quanto a ter aulas com um professor mais jovem, até mesmo para manter o status do professor deles ainda em suspenso.

Em linhas gerais, a Aluna 1 apontou que o professor é bastante organizado com o planejamento das aulas e com os feedbacks e que estabelece uma boa comunicação com os alunos. O Aluno 4 afirmou que aulas são bastante dinâmicas e participativas, e que isso seria "coisa de professor jovem" (ALUNO 4). Segundo ele, isso acontece porque o professor está muito mais próximo dos alunos, o que muitas vezes torna seus exemplos mais fáceis de entender. O Aluno 5, por fim, relatou ter tido aulas no semestre anterior com uma professora também jovem e que estava assumindo sua primeira turma. "No 
começo ela mesma admitiu que era a primeira turma, estava nervosa, mas eu acho que com as aulas ela foi se soltando e eu, pelo menos, adorei a aula dela." (ALUNO 5) ${ }^{9}$.

As últimas perguntas programadas para a roda de conversa buscaram investigar se os alunos veem os estagiários mais como assistentes ou se conseguem ver neles um professor regente da turma ao longo do semestre, o que acabou retomando as questões levantadas pelo Aluno 6 anteriormente. Sendo assim, a mediadora começou perguntando o que eles pensavam de estagiários atuarem como auxiliares de outros professores em sala de aula. O aluno que se manifestou de forma mais enfática quanto aos estagiários assumirem turmas sozinhos respondeu: "Eu acho que é assim que deve ser, auxiliar e sempre com a supervisão do professor orientador, mas nunca dar a responsabilidade de uma turma inteira para o estagiário." (ALUNO 6). Os demais participantes, de forma geral, concordaram. Eles apontaram que, assim, os estagiários estariam aprendendo com alguém que já tem mais experiência e ao mesmo tempo estariam auxiliando outro professor. Alguns ainda afirmaram que isso pode ser positivo para os alunos. Por exemplo, o Aluno 5 chamou atenção para o tamanho das turmas e para o fato de que um professor sozinho pode não conseguir supervisionar e ajudar todos os grupos ao mesmo tempo, uma vez que os materiais e as aulas focam bastante em práticas de conversação.

Perguntamos aos alunos, então, se eles acreditam que os estagiários estão prontos para dar aulas sozinhos. A primeira aluna a responder afirmou: "O problema [é] da instituição mesmo no preparo das pessoas." (ALUNA 1). O Aluno 4 disse acreditar que depende muito de uma pessoa para a outra, e da preparação de cada um. Porém, ele apontou que o estagiário poderia apresentar um planejamento a um professor mais experiente e que este supervisionaria a aplicação durante sua aula. Afirmou, ainda, que “tendo uma turma só pra ele é muita responsabilidade", e que, por isso, talvez o estagiário não consiga "passar [transmitir] bem" (ALUNO 4) todos os conteúdos.

Nesse momento percebemos, novamente, a fragmentação e complexidade das perspectivas dos alunos, pois esse mesmo aluno afirmou anteriormente que não importa quem está na frente da turma ou de onde essa pessoa veio, desde que esteja fazendo um bom trabalho. Ele encerrou apontando que alguns estagiários talvez consigam, mas não todos, e acha que não tem como medir se eles realmente estão prontos ou não sem ser na

\footnotetext{
${ }^{9}$ Por curiosidade, consultamos a distribuição de turmas do semestre anterior e descobrimos que a professora 
prática, e por isso acredita que existem chances de que um estagiário faça um bom trabalho $^{10}$. O Aluno 5 disse que talvez para os níveis mais básicos sim, mas que, para os níveis mais avançados, a presença de um professor supervisionando seria essencial pois os alunos teriam mais confiança em um professor mais experiente. Ou seja, os alunos parecem entrar em contradições, que poderiam ser resumidas em uma frase: $o$ Celin deve, sim, dar oportunidades para professores iniciantes, mas talvez não para serem os meus professores. Todavia, uma das alunas disse concordar em partes com os demais alunos, pois "O estagiário vai ganhar com a experiência. Ele tem que estar na sala de aula para ter essa experiência." (ALUNA 2).

\section{NOSSAS PERCEPÇÕES A PARTIR DE NOSSAS LEITURAS}

Antes de darmos início a esta seção, é importante retomarmos o fato de que esta é uma pesquisa qualitativa que trata de uma realidade bastante específica. Nossa intenção não é propor generalizações ou abstrações sobre as relações estabelecidas entre professores estagiários e alunos, nem mesmo dizer que todos os discentes e docentes do Celin e de outras escolas de idiomas partilham de nossas reflexões. Por essa razão, escolhemos a etnografia, pois, assim como dito por André (2012, p. 25), "a pesquisa etnográfica busca a formulação de hipóteses, conceitos, abstrações, teorias e não sua testagem", ela "visa a descoberta de novos conceitos, novas relações, novas formas de entendimento da realidade".

Nosso intuito, portanto, foi compartilhar um relato de nossas experiências e, possivelmente, dialogar com outros professores e pesquisadores que estejam interessados em questões parecidas. Somos professores de inglês, ex-estagiários, e construímos um relato a respeito de nossas experiências dentro de uma das diversas áreas de um centro de línguas bastante heterogêneo e diverso. Sabemos, portanto, que este estudo trata de

em questão era uma das estagiárias da área de inglês na época do estudo.

${ }^{10}$ Esse mesmo aluno trouxe outra questão interessante ao afirmar que ainda que o estagiário seja muito fluente no inglês ("cursado, viajado"), podem haver coisas que ele não consiga passar para os alunos. Acredita que um professor com mais experiência saiba várias estratégias para ensinar e explicar o mesmo assunto e tenha "um leque a mais de opções" (ALUNO 4) para certas situações que surgem no decorrer das aulas. Essas colocações são importantes pois mostram que esse aluno parece entender que para ser um bom professor de inglês não basta ter experiências com viagens e vivência internacional, que é o que muitas dessas escolas tradicionais apontam como um dos pontos que diferencia seus professores e porque esses seriam melhores profissionais. 
interpretações e percepções a respeito de histórias construídas através de nossas lentes na vivência com nossos alunos e colegas do Celin.

Ao analisarmos os dados obtidos por meio da roda de conversa, pudemos averiguar que os alunos trazem consigo à sala de aula noções pré-concebidas não apenas acerca do que seria a língua inglesa e seu aprendizado, mas também quanto à figura do professor estagiário e ao papel do Celin enquanto instituição de excelência, comumente associada à imagem da UFPR e da ideia de qualidade das instituições federais - o que nos remete ao trabalho de Stuart Hall quando nos diz que as identidades culturais são "formadas e transformadas no interior da representação" (2005, p. 49, grifo do autor). Em outras palavras, as pessoas identificam a si mesmas e aos outros por meio de um discurso, presente na sociedade, que influencia o modo como veem o mundo e entendem as coisas. Isso pode ser associado à noção de estereótipo, uma imagem ou construção que se tem de certo sujeito ou objeto, e que guiará um entendimento previamente estabelecido a respeito dele. Quando nos voltamos à figura do estagiário, por exemplo, podemos perceber que há a forte presença de um estereótipo influenciando a visão dos alunos. Talvez por experiências anteriores que não foram satisfatórias ou até mesmo por um discurso bastante presente na sociedade de que estagiários seriam pessoas inexperientes e, por vezes, sem qualificação, há certo tipo de resistência por parte dos alunos. Todavia, os mesmos alunos que levantam dúvidas quanto à capacidade de um estagiário ser responsável por uma turma são os mesmos que elogiam a dedicação do professor ainda em formação inicial sem ter o conhecimento de sua posição dentro da instituição. Essa oscilação de opiniões aponta para o conceito de "sujeitos fragmentados" (HALL, 2005, p. 12), os quais seriam sujeitos constituídos por identidades diversas e até mesmo "contraditórias ou nãoresolvidas", o que seria o caso da figura do estagiário.

É possível notar que a representação tida dos estagiários como pessoas inexperientes é o que acaba gerando insegurança nos alunos, pois estes não veem problema algum em ter aula com pessoas jovens, sejam elas mais novas ou da mesma faixa etária. O que preocupa os alunos é a suposta falta de qualificação profissional por parte dos professores possivelmente atrasar seu aprendizado. Portanto, eles ressaltam a importância da supervisão do estagiário por parte da instituição e de professores mais experientes. Nesse sentido, para que a experiência tanto dos alunos como dos estagiários 
possa ser proveitosa, o acompanhamento e a formação desses professores iniciantes devem ser vistos como prioridades.

Para nós, essa desconfiança dos alunos para com os estagiários e o desejo de não ser parte da turma de um deles é evidência de que há fundamentação para nossas asserções: i) o Celin possui um caráter formador, mas esse parece estar se perdendo ao longo dos anos e iii) essa perda pode ser observada na área de inglês no que diz respeito à formação inicial, i.e. na presença (e na falta) dos estagiários. Acreditamos que uma reformulação no modo como a instituição e os cursos são apresentados aos alunos seja necessária, uma vez que parece não estar claro para os alunos que um dos papéis do Celin é proporcionar experiências de formação inicial aos discentes de Letras da UFPR.

Essas reflexões nos levam ao seguinte questionamento: os alunos e os professores estagiários, nesse contexto, estariam passando por uma crise de identidade? Segundo Kobena Mercer, "a identidade somente se torna uma questão quando está em crise, quando algo que se supõe como fixo, coerente e estável é deslocado pela experiência da dúvida e da incerteza" (MERCER, 1990, p. 43 apud HALL, 2005, p. 9). As opiniões dos alunos acerca da capacidade dos estagiários, i.e. a necessidade de que estes tenham experiência lecionando e que não viam problema em ter professores iniciantes dando aulas, são postas em questão durante um momento de dúvida e incerteza quanto a eles próprios terem aula com um estagiário. Pode-se cogitar uma crise de identidade tanto por parte dos alunos, incertos acerca do que eles mesmos pensam, como da representação tida por eles dos estagiários e do imaginário que eles trazem consigo a respeito dessa figura.

No que diz respeito às noções que os alunos têm sobre a língua e seu aprendizado, Jordão (2006), ao discutir concepções de língua enquanto código ou enquanto discurso, aponta que

ao ensinar línguas estrangeiras, os professores e seus alunos adentram as salas de aula munidos de uma ou várias séries de pressupostos sobre o que seja uma língua, sobre o processo de ensino/aprendizagem daquela língua, sobre seu capital cultural no contexto social em que se insere (JORDÃO, 2006, p. 1).

A autora afirma que esses pressupostos muitas vezes não vão ao encontro de teorias sendo desenvolvidas na área que estuda o ensino e aprendizado de línguas, pois na verdade são frutos de construções discursivas desenvolvidas em diferentes comunidades e 
partilhadas entre os sujeitos em suas comunidades.

Seguindo a reflexão com Jordão, em uma perspectiva estruturalista de língua, que separa o sistema linguístico de seu uso,

concebe-se a língua como um intermediário entre o sujeito e o mundo; a língua daria acesso ao mundo, permitiria que agíssemos nele. Consequentemente, a realidade aqui é concebida como algo externo ao sujeito, independente dele. A língua representaria esse mundo para nós, ao mesmo tempo em que nos permitiria acesso a ele (JORDÃO, 2006, p.2).

Segundo a autora, as discussões a respeito do ensino e aprendizado de línguas passam a inserir o sujeito e sua realidade à medida que "[o] pós-estruturalismo procede à desconstrução de pressupostos, ao questionamento das noções menos conscientes e das estruturas a partir das quais promovemos nossos entendimentos do mundo" (JORDÃO, 2006, p. 4). Ou seja, nessa virada, as línguas deixam de ser concebidas como sistemas linguísticos abstratos e externos aos sujeitos. Os alunos e professores estão usando a língua constantemente, se colocando nela, construindo suas identidades à medida que criam e recriam o que se entende como conhecimento linguístico.

Podemos dizer então que muitos dos alunos carregam uma noção de caráter mais estruturalista consigo, i.e. o discurso daqueles que acreditam que precisam aprender inglês para adquirir mais autonomia. Todavia, não apenas os alunos carregam essas noções por si, mas também são levados a isso por conta da estruturação dos cursos que experienciam. Isso fica evidente quando voltamos à percepção quanto às provas que são realizadas no decorrer das aulas de inglês do Celin. Para os alunos que participaram da roda de conversa, a segmentação das provas de acordo com as diferentes competências é necessária, além do fato de eles não terem identificado problemas na cobrança de avaliações explícitas de gramática descontextualizada.

Acreditamos que, assim como no caso dos estranhamentos em relação aos estagiários, essas visões de língua e ensino mais estruturalistas por parte dos alunos sejam fruto das concepções de língua e aprendizado às quais eles estão sendo expostos. Nossa hipótese é de que isso possivelmente seja resultado da falta de abertura para os professores ainda em formação inicial que apontamos anteriormente, ou seja, em vez de espaços como o Celin propiciarem a construção e experimentação de práticas de sala de aula mais 
inovadoras, os estagiários e professores do centro acabam por repetir a organização tradicional de institutos de idiomas. Ao fim e ao cabo, os professores estagiários, nessa etapa de formação, são os que mais estão em contato com essas abordagens de caráter pósestruturalista debatidas atualmente nas licenciaturas em Letras e que poderiam renovar constantemente as práticas de sala de aula de espaços como o Celin.

Todavia, ficamos otimistas ao perceber que, apesar das problematizações apresentadas até então, discussões acerca do Inglês como Língua Franca parecem estar chegando até as salas de aulas do Celin. Temos evidências disso pois em nenhum momento da roda de conversa a questão do falante nativo ou de vivência internacional dos docentes é priorizada pelos alunos em detrimento da experiência e da formação dos professores $^{11}$. Nesse sentido, há o trabalho de Galor e Haus (2019), também desenvolvido com turmas de inglês do Celin, no qual os autores apresentam atividades que, por exemplo, além de questionar o espaço ocupado pela língua inglesa na atualidade, incluem diferentes variedades de inglês produzidas por falantes não-nativos.

Além disso, houve uma iniciativa realizada por parte dos estagiários que atuavam na área de inglês no segundo semestre de 2019 que propôs uma quebra dos moldes tradicionais dos cursos em execução no Celin: o Open Pre Intermediate foi um curso de extensão, com encontros semanais e duração total de 60 horas, aberto para alunos de todos os níveis. Ao longo das aulas, os professores trabalhavam sempre em duplas ou trios e não seguiam materiais didáticos pré-estabelecidos. As atividades eram sempre elaboradas em conjuntos e tendo em vista o público-alvo específico e as necessidades apontadas pelos próprios alunos e observadas ao longo das aulas. Por fim, os alunos não passaram por avaliações formais e/ou focadas em apenas uma competência isolada, uma vez que foram desenvolvidos projetos de caráter bastante participativo cujo intuito era tentar avaliar os alunos de forma mais holística.

A partir dessas atuações é possível perceber que há abertura para uma postura calcada em perspectivas de ensino mais recentes, tais como o pós-método (HALL, 2016) e

\footnotetext{
${ }^{11}$ No entanto, também é possível encontrar discursos contrários com outros alunos do Celin, como foi o caso em uma das respostas que recebemos no questionário on-line: "Estagiários deveriam ser o suporte para os professores, como para auxiliar nas dúvidas dos alunos, mas como titulares, ainda deixam a desejar em alguns aspectos, como vivência no exterior, curiosidades, maior domínio na língua, atividades mais diretas, maior clareza e menos enrolação para explicar a matéria." (Aluno anônimo em resposta ao questionário online, grifo nosso).
} 
o Letramento Crítico (FOGAÇA; JORDÃO, 2007, JUCÁ; FUKUMOTO; ROCHA, 2011). Os próprios alunos do Celin percebem que o foco das aulas é a conversação, considerando a prática social da língua. Além disso, os professores da área de inglês constantemente compartilham entre si atividades pautadas na reflexão e criticidade a respeito dos mais variados temas que são propostos para as aulas. Isso acontece pois, ao ensinar a língua, devemos ir além dos aspectos linguísticos; precisamos ter em vista objetivos educacionais, sociais e culturais, que façam a língua ser mais do que apenas um "instrumento" de comunicação (JUCÁ; FUKUMOTO; ROCHA, 2011).

Nesse sentido, o Celin é uma instituição formadora, e isso se estende não apenas aos profissionais que lá trabalham mas também aos alunos do Centro de línguas. Portanto,

é importante que estejamos prontos para identificar e desafiar constantemente nossos pressupostos e suas implicações: ao fazê-lo, podemos entender mais facilmente de onde eles vêm, como se formam e quais as suas consequências em termos de ações, escolhas, estabelecimento de valores e julgamentos (JORDÃO, 2006, p. 1).

Acreditamos, então, que não só a área de inglês e seus professores, mas todos aqueles que têm a oportunidade de trabalhar em espaços e projetos de extensão como o Celin devam aproveitar essa oportunidade para assumir uma posição de constante reflexão e atualização de suas práticas. Como foi possível observar pelas reflexões trazidas neste estudo, alguns avanços são perceptíveis, mas ainda há pleno espaço para mudança.

\section{CONSIDERAÇÕES FINAIS}

Ao longo da construção deste relato, pudemos verificar que há de fato um afastamento do Celin em relação aos seus objetivos iniciais, especialmente no que tange a questão de um local para formação inicial de professores. Se considerarmos a diferença do número entre professores estagiários e contratados, acreditamos que isso pode ser decorrente da permanência dos mesmos profissionais na área de inglês por um longo período de tempo, às vezes além de seu período de formação. Além disso, ainda que existam diversos estereótipos quanto à figura do estagiário, concordamos com os alunos quando eles apontam que esses precisam de mais acompanhamento e oportunidades para trabalhar em colaboração com docentes mais experientes. Partindo de nossas experiências 
como ex-estagiários, entendemos que isso seria benéfico não apenas para a formação desses professores, mas também para que os alunos consigam entender melhor a presença dos estagiários nas salas de aula, tendo em vista que o Celin é, também, um projeto voltado à formação de professores.

Os dados apresentados e discutidos nesta pesquisa, como mencionamos anteriormente, foram produzidos durante o segundo semestre de 2018 e primeiro semestre de 2019. Desde então, o Celin começou a apresentar mudanças que podem ser vistas como evidência de que outras pessoas em outros lugares também se questionaram sobre questões como as que apresentamos neste relato. No final do ano de 2019, por exemplo, a instituição lançou um edital geral, recrutando cerca de 54 estudantes bolsistas, em diferentes categorias, para atuar em atividades de docência e pesquisa em diversas áreas e línguas ${ }^{12}$. Além disso, a pandemia do novo coronavírus e a paralisação das atividades durante o ano de 2020 também podem apresentar impactos sem precedentes para o centro de línguas.

Convidamos, portanto, professores e pesquisadores que também se interessem pelos questionamentos discutidos neste trabalho para olhar suas realidades específicas e construir relatos sobre seus contextos. Somos confiantes de que, sendo o Celin um ambiente de pesquisa e formação, esse é um debate que está em construção constante e que outras experiências podem vir a ser fruto para pesquisas futuras.

\section{AGRADECIMENTOS}

Os autores gostariam de agradecer às professoras Juliana Zeggio Martinez, Regina Célia Halu e Angela Maria Hoffmann Walesko pela orientação, leitura e apoio, essenciais para a realização deste estudo. Ao Celin por ser um espaço de muito aprendizado durante nossa formação. Além disso, não podemos deixar de agradecer aos colegas Valéria Luize Silva, ex-professora estagiária do Celin, e Bryan Pissinini, professor do Celin e bolsista do CAPA (Centro de Assessoria de Publicação Acadêmica - http://www.capa.ufpr.br/portal/) da UFPR pela leitura e revisão do manuscrito.

\section{REFERÊNCIAS}

ANDRÉ, M. E. D. A. de. Etnografia da Prática Escolar. Campinas: Papirus, 2012.

\footnotetext{
${ }^{12}$ Mais informações disponíveis em: <encurtador.com.br/bjquB >. Acesso em: 24 jun. 2020.
} 
BORTONI-RICARDO, S. M. O professor pesquisador: introdução à pesquisa qualitativa. São Paulo: Parábola Editorial, 2008.

FIGUEIREDO, E. H. D. de.; MARTINEZ, J. Z. The locus of enunciation as a way to confront epistemological racism and decolonize scholarly knowledge. Applied Linguistics, v. amz, p. 1-6, 2019.

FOGAÇA, F. C.; JORDÃO, C. M. Ensino de inglês, letramento crítico e cidadania: um triângulo amoroso bem-sucedido. Linguas \& Letras, v. 8, n. 14, p. 79-105, 2007.

GALOR, A. L.; HAUS, C. O ENSINO DE INGLÊS COMO LÍNGUA FRANCA: UM RELATO DE PRÁTICAS. PERcursos Linguísticos, v. 9, n. 22, p. 254-274, 2019

HALL, G. Method, methods and methodology historical trends and current debates. In: HALL, G. The Routledge Handbook of English Language Teaching, p. 209-223, Nova Iorque: Routledge, 2016.

HALL, S. A identidade cultural na pós-modernidade. 10 ed. Rio de Janeiro: DP\&A, 2005.

HALU, R. C.; FOGAÇA, F. C. A expansão da língua inglesa e seu impacto nos professores universitários de inglês em cursos de letras: um diálogo reflexivo. Revista X, Curitiba, v. 13, n. 2, p. 1-14, 2018.

JORDÃO, C. M. O ensino de línguas estrangeiras - de código a discurso. VAZ BONI, Valéria. (Org.). Tendências Contemporâneas no Ensino de Línguas. União da Vitória: Kaygangue, 2006.

JUCÁ, L.; FUKUMOTO, A. HB; ROCHA, A. O Letramento Crítico e a formação do professor-cidadão: caminhos possíveis para a transformação da prática e da posição docentes. Revista X, v. 1, n. 1, 2011.

UNIVERSIDADE FEDERAL DO PARANÁ (UFPR). Centro de Línguas e Interculturalidade. Relatório 20 anos de Celin: 1995 - 2015. Curitiba: UFPR, 2015. 


\begin{abstract}
ANEXO I
Questionário: O que significa estudar no Celin?

Este formulário buscou obter uma percepção inicial sobre a visão dos alunos a respeito do ensino e aprendizado de inglês no Celin UFPR.
\end{abstract}

O que te levou a escolher o Celin para aprender inglês?

Você estudou inglês em algum lugar antes de entrar no Celin?

Se sim, você acha que o Celin apresenta uma abordagem... (Similar à $(s)$ outra $(s)$ escola $(s)$ que estudei; Muito similar à(s) outra(s) escola $(s)$ que estudei; Diferente da(s) outra(s) escola(s) que estudei; Muito diferente da(s) outra(s) escola (s) que estudei)

Referente à pergunta anterior, você poderia justificar sua resposta?

O que você procura alcançar com o aprendizado de inglês?

Você acha possível alcançar seu objetivo por meio da abordagem utilizada pelo Celin?

Com relação às avaliações: $\mathrm{O}$ quão úteis você as julga? Considere 1 como inútil/dispensável e 5 como extremamente importante (Reading, Listening, Speaking, Writing e ProgressCheck).

Você se incomoda em ter aula com estagiários?

Deseja fazer algum comentário sobre a questão acima?

Por fim, o que significa estudar inglês no Celin para você? 


\section{ANEXO II \\ RODA DE CONVERSA COM ALUNOS/AS}

1. Como vocês conheceram o Celin? O que os levou a escolher o Celin para aprender inglês?

(Para averiguar se eles já possuem contato com outras realidades)

2. Você estudou inglês em algum lugar antes de entrar no Celin? Você acha que a abordagem das aulas do Celin é diferente dos outros lugares em que estudou?

(Para ver se os alunos conseguem fazer relações entre essas possíveis outras escolas e o Celin)

3. Por que vocês estão aprendendo Inglês?

(Para ver se algum deles gostaria de fazer aqueles testes, etc x Porém, pode caminhar junto com a questão da democratização do ensino e de dar acesso ao aprendizado de línguas para quem antes talvez não tivesse).

4. Você acha que o Celin irá te ajudar a alcançar os seus objetivos em relação ao aprendizado de Inglês?

(Muito ligado à pergunta anterior. Alguns alunos às vezes se decepcionam com o fato de o curso não os preparar para testes de proficiência).

5. (A depender do tempo) Perguntar sobre as avaliações (PC, Reading, Listening, Speaking, Writing). O que eles acham, etc.

(O método de avaliação é bem tradicional, acreditamos que essa pergunta possa gerar alguns dados interessantes).

6. Você já teve aulas com estagiários? Qual a sua opinião sobre estagiários dando aula no Celin?

(Alguns dos alunos da turma não sabem que o professor é estagiário, essa pergunta visa avaliar qual a percepção geral dos estudantes sobre o tema)

7. Para os que já tiveram aulas com outros professores contratados: percebem alguma diferença? Quais?

8. Alguns estagiários apenas observam e auxiliam os professores em algumas atividades. O que vocês acham disso? Vocês acreditam que os estagiários estão prontos para dar aulas?

(As duas perguntas anteriores visam um aprofundamento de questões já observadas com os questionários).

Recebido em: 05 jul. 2020.

Aceito em: 11 ago. 2020. 